Horizons philosophiques

\title{
Le problème de l'indexicalité idéologique des discours sur la mondialisation de la culture
}

\section{Brigitte Beauzamy}

Volume 15, numéro 2, printemps 2005

Cultures ou mondialisation?

URI : https://id.erudit.org/iderudit/801289ar

DOI : https://doi.org/10.7202/801289ar

Aller au sommaire du numéro

Éditeur(s)

Collège Édouard-Montpetit

ISSN

1181-9227 (imprimé)

1920-2954 (numérique)

Découvrir la revue

\section{Citer cet article}

Beauzamy, B. (2005). Le problème de l'indexicalité idéologique des discours sur la mondialisation de la culture. Horizons philosophiques, 15(2), 1-14.

https://doi.org/10.7202/801289ar d'utilisation que vous pouvez consulter en ligne.

https://apropos.erudit.org/fr/usagers/politique-dutilisation/ 


\section{Le problème de l'indexicalité idéologique des discours sur la mondialisation de la culture}

Dans l'univers du discours sur la mondialisation, c'est-à-dire l'ensemble des textes, quel que soit leur genre, qui traitent du phénomène de mondialisation, celui sur la mondialisation de la culture mérite une attention spécifique. En effet, la mondialisation est en général comprise comme un phénomène d'abord économique, ce qui implique l'usage de dérivations pour caractériser d'autres mondialisations : tel est le cas de la mondialisation de la culture. Cette dérivation se branche sur un univers du discours dynamique, hostile dans son intention, et dont l'adversaire est généralement (néo-)libéral. Le discours autour de la mondialisation de la culture part lui aussi d'une critique du libéralisme : il est marqué par un recyclage pessimiste des thèses et des imaginaires libéraux et mondialistes, l'idéal d'un véritable universalisme apparemment impossible dans les faits rencontrant les valeurs de tolérance des altérités et les théories du respect des cultures multiples. Cette ambivalence, dans la perspective générale des discours sur la mondialisation, amène à des concepts paradoxaux comme celui d'un «universalisme respectueux des différences". Cette charge hostile contre la mondialisation part de la dénonciation du caractère utopique de la foi en l'universel occidental moderne. Le constat d'échec de celui-ci conduirait à des conclusions contradictoires, d'une part de crainte de la montée de "particularismes" - non occidentaux, et considérés comme non modernes - et, d'autre part de souhait sincère que soient mises en place des politiques destinées à protéger ces cultures non occidentales des rigueurs de la modernité. Le point qui nous intéresse ici, et qui sera démontré à partir d'un corpus de référence limité et francophone, pour des raisons d'espace, est de montrer que les discours sur la mondialisation de la culture défient bien souvent les tentatives de classification politique. Ce corpus est constitué de textes de vulgarisation des grands débats sur la mondialisation, qui n'ont donc pas été produits avec une visée directement militante : ceci met en évidence le fait que le discours sur la mondialisation de la culture permet, encore davantage que celui sur la «mondialisation néo-libérale», 
la formulation d'arguments isomorphes donnant lieu à des usages politiques opposés.

\section{Définition de la culture dans la mondialisation : peuple et nation}

Le raisonnement part d'une définition de la culture, dont les auteurs déclarent longuement en préliminaire qu'ils sont incapables de l'établir de manière univoque. Ils insistent sur le caractère pluriel de la culture, et sur le fait que toute tentative de définition résulte d'un choix : "La notion de "culture" est multiple, diversifiée et polysémique (...) II faut assumer cette multiplicité et cette hétérogénéité qui font partie même de la substance culturelle ${ }^{1}$ ». Ils le font tout de même : "Serrons d'abord de plus près la notion de culture. Celle-ci se caractérise par son mode de transmission, que l'on désigne comme tradition ${ }^{2}$. Qu'est-ce à dire de ces précautions de langage? Elles annoncent une perspective dans laquelle la définition de la culture va être un instrument de la démonstration - «ll appartient à chaque individu, chaque groupe et chaque institution de produire sa propre définition selon ses besoins ${ }^{3}$ " mais révèlent également le fait que cette définition n'est pas évidente, soit comme corpus savant, soit comme cadre transparent de la vie dans une civilisation, mais qu'elle fait l'objet d'un enjeu - dont les discours sur la mondialisation se saisissent.

La perspective de la mondialisation dirige cette impossible définition de la culture dans deux directions : la localisation de la culture et sa stabilité dans le temps. II faut noter que les auteurs se situent dès le départ dans une perspective où ils vont considérer une pluralité de cultures - et donc ne pas adopter le point de vue singulier d'une d'entre elles. Les auteurs se trouvent alors en demeure de réaliser une cartographie classificatrice ${ }^{4}$; pour cela, sont choisies les conditions physiques de leur existence, en particulier géographiques : "Comment (...) opérer le découpage entre les différentes entités socioculturelles? (...) II n'existe aucune réponse universelle à de telles questions. Tout dépend de ce que l'on souhaite analyser. Or, ce que nous voulons analyser, ce sont les turbulences culturelles à l'époque actuelle. Au regard de la mondialisation des marchés, les cultures apparaissent comme "localisées" 5 ". Le point de départ et d'arrivée reste l'État-nation en tant que cadre de référence : "Dans la majorité des cas, cette localisation est géographique. (...) En définitive, "au regard de la mondialisation de la culture", les unités 
qui nous semblent les plus pertinentes sont les États nations (...) ou les groupes ethniques à cheval ou non sur plusieurs frontières étatiques, ou dispersés à travers le monde". Effectivement, seul un point de vue partant de la mondialisation peut amener à considérer comme première caractéristique de la culture sa localisation. Nous nous trouvons donc face à la caractéristique principale des discours sur le mondial : ils font apparaître le local, d'ordinaire transparent.

Le deuxième critère de découpage des cultures, qui doit s'avérer relativement stable à l'observation, a trait à leurs contenus définis comme un ensemble de «normes, d'habitudes, de répertoires d'action et de représentation ${ }^{6}$ : : la culture est donc vouée à la reproduction plus qu'à la production, et se présentera davantage comme la structure inconsciente du comportement de l'individu que comme l'objet de ses capacités créatrices. Cette culture d'un groupe clos encadre le comportement des individus, détermine les représentations et les actions de ses membres par le biais de l'identité, qui apparaît comme une catégorie surplombant l'individu, doublement hétéronome parce que liée aux contingences de la naissance et de la socialisation primaire à caractère quasi-biologique :

"la tradition, ce par quoi se transmet la culture, nous imprègne dès l'enfance de manière indélébile, corps et âme. Par exemple, un individu qui n'a pas appris une langue dans l'enfance et ne l'apprend qu'à l'âge adulte la parle rarement sans accent. La raison en est que son appareil phonatoire n'aura pas assimilé les mouvements qui permettent de produire correctement les sons d'une langue donnée ${ }^{7}$ ".

Le thème de la langue natale connaît un certain succès dans les textes sur la mondialisation de la culture; ainsi, Françoise Wuilmart, en tant que traductrice, écrit-elle un texte intitulé «Mondialisation, écriture et traduction» où elle affirme se situer dans la lignée de J.-P. Warnier ${ }^{8}$. Elle associe le thème de la langue à celui des «racines» et illustre son propos d'une longue citation de J. Amery dans laquelle il se livre à un vibrant plaidoyer pour la défense de la patrie et des valeurs nationales opposées à un cosmopolitisme décadent :

«Est-ce un malheur pour l'homme de perdre sa terre natale ou sa patrie? Oui! Car il grandit avec l'espace qu'il considère tout naturellement comme sien (...) L'homme moderne troque sa terre contre le monde. Quelle brillante affaire! (...) Car ils sont 
nombreux ceux qui, en troquant la "patrie" d'hier contre un cosmopolitisme de deuxième classe, lâchent la proie pour l'ombre, la terre pour la chimère. (...) Je prétends donc que la terre natale, c'est la sécurités".

Elle aussi reprend l'exemple de l'impossibilité d'apprendre parfaitement une langue étrangère - «Une langue artificiellement apprise par la suite et géographiquement coupée de sa culture ne sera jamais sentie ou vécue avec la même force d'évidence ou la même proximité que la langue maternelle ${ }^{10}$,. - , la langue devenant la métonymie de la culture comme nation et peuple. Cette culture a un usage : c'est une «boussole»11 à l'usage de ses membres, sans laquelle le monde serait "une cacophonie et un désordre bien pires que ceux que nous connaissons". Mais il apparaît clairement que cette boussole ne sert pas à s'éloigner de son point de départ national.

\section{Universalisme et particularisme}

Le discours sur la mondialisation de la culture apparaît comme durablement en tension entre les pôles de l'universalisme et de la défense des particularités. Le thème de la mondialisation de la culture n'égratigne pas le postulat, hérité du mondialisme, qu'il existe un progrès dans lequel les relations entre les peuples tendent vers une tolérance mutuelle éclairée. Ainsi dans le cas de J.-P. Warnier, alors que l'auteur s'attache nettement à fonder scientifiquement son propos, ce qu'il souligne par son recours à une neutralité vigilante vis-à-vis de l'ethnocentrisme, à l'objectivité et à la nuance, l'emprise d'un paradigme mondialiste universaliste est manifeste. Cela donne lieu à des contradictions qui révèlent tant la difficulté de donner une appréciation éthique des phénomènes étudiés que la nécessité ressentie d'une telle appréciation, non pas seulement pour les juger mais aussi pour les comprendre. Ainsi, si l'auteur établit une critique vigoureuse de l'inégalité des flux de "produits culturels" et de la marchandisation de la culture, il part cependant du postulat que ces flux sont fondamentalement positifs - «Quel prix ne faut-il pas payer, en temps et en énergie, pour faire sortir les communautés locales de leur isolement et de l'extrême fragmentation des cultures? ${ }^{12}$ 》 - avant. de déplorer l'«inégalité devant les flux mondiaux de la culture industrialisée ${ }^{13}$ ". De la même manière, tout en déplorant les méfaits d'une complète soumission des échanges de produits culturels aux impératifs de rentabilité, et en appelant à la création d'une 
"Organisation mondiale de la culture, une OMC bis, capable de tenir tête à la première, celle du commerce» il note que "l'essor des médias et la croissance économique vont de pair». et que «nombreux sont les observateurs qui se sentent pris dans le dilemme suivant : ou bien sacrifier la démocratisation de la planète à l'exception culturelle, ou bien l'inverse ${ }^{14}$ ".

La démonstration qui se construit à partir de cette perspective universaliste est teintée du regret que celle-ci mise en pratique ait trop souvent coïncidé avec une occidentalisation forcée et la destruction des "cultures singulières". L'existence de ces contradictions entre différentes positions éthiques est moins révélatrice de l'indécision de l'auteur que de l'emploi de concepts peu maniables dotés dès le départ d'une coloration laudative ou péjorative pour décrire les phénomènes discutés, quitte à en changer par la suite. II est probable qu'on ne peut pas réfléchir sur la mondialisation de la culture en suspendant, au moins pour le temps de la démonstration, le jugement éthique, car, dans l'univers du discours considéré, ni le concept de mondialisation, ni celui de culture, ne permettent cette neutralité.

La solution adoptée consiste alors à scinder le concept d'universalisme en deux (à l'imitation des couples d'oppositions artificielles mondialisation/globalisation) en distinguant le bon universalisme du mauvais. Cette distinction recouvre de fait celle entre art noble et culture de masse : ainsi, chez F.Wuilmart la "mauvaise traduction (...) rabote les particularités pour aboutir à une sorte de panacée universelle, mais d'universalité hautement suspecte qu'elle compare au "petit pain de Mc Donald's" (...) Le rôle du traducteur est d'éviter ce type de mondialisation ravalante et d'universalisation néfaste ${ }^{15}$ " qui rend l'œuvre «extra-territoriale à son contexte culturel». À l'inverse, le mode d'accession d'un "grand texte» à "sa pérennité et son universalité», c'est son idiosyncrasie extrême puisque, au-delà de la culture dans laquelle il s'inscrit - et qui est nationale -, c'est l'individualité même de l'auteur qui la fonde : il "accède à l'universel par le biais du particulier ${ }^{16}$ », par le fait que les lecteurs du monde entier s'identifieront à celui-ci par le biais de la catharsis. À cette lecture trans-nationale, l'auteure prête toutefois les vertus pacificatrices usuellement associées à l'universalisme mondialiste, en affirmant que «le premier foyer de la tolérance, est le soi particulier, animé de la conscience sécurisante d'une identité culturelle ${ }^{17}$ \%, sans que le mode d'action de celles-ci soit explicité. L'universalité tolérante proviendrait ici d'une relation entre deux individualités fortement 
nationales, celle de l'auteur et celle du lecteur, qui s'oppose au paradigme de la diffusion massive et mondiale des produits culturels.

\section{Libéralisme trans-national et choc des cultures}

Le raisonnement autour de la mondialisation de la culture part nécessairement du marché, considéré à la fois comme phénomène majeur de la modernité et comme norme naturelle de l'action économique : "La mondialisation de la culture est une des conséquences du développement industriel. L'ambition normale de toute industrie culturelle est de conquérir des parts du marché mondial en diffusant ses productions au Sri Lanka comme aux États-unis ${ }^{18}$ ". Le cadre libéral est présenté comme mondial S. Cordellier souligne sa parenté avec la notion, chère aux pamphlets nationaux-socialistes, de "mondialisme apatride»19. La représentation du libéralisme, dans le domaine de la culture, se confond avec celle de la production en série de produits diffusés en masse partout dans le monde. Cette production est le fait d'une catégorie particulière d'acteurs du monde économique, les industries culturelles, créées à l'intersection du marché - et du mode de production industrielle spécifique avec lequel il semble lié, la série - et de cet ensemble flou qu'est la culture, à la fois cadre anthropologique de la vie quotidienne, et production, en particulier d'œuvres. II est possible dès lors de renverser le raisonnement en les considérant comme le produit de la culture-tradition des sociétés industrielles, et cette «industrie comme culture" entre en concurrence avec les autres cultures-tradition pour la détermination des structures sociales d'une société donnée. Le raisonnement consiste ici, pour qualifier des frottements entre des sociétés définies comme traditionnelles et d'autres définies comme modernes-occidentales, à étendre à ces dernières des concepts et des modes de raisonnement jugés efficaces pour les premières. Dans cette perspective, le capitalisme, les révolutions industrielles et le libéralisme - mais aussi d'autres formes de raisonnement essentielles à la modernité comme le rationalisme scientifique apparaissent comme des systèmes de croyance qu'on peut mettre en parallèle valablement avec la kula ou les pratiques de sorcellerie.

Dès lors, les «sphères» - économiques, politiques, culturelles dans lesquelles s'étend la mondialisation sont subsumées à celle de la culture qui, en tant que synonyme de la civilisation, les prend toutes en charge. On ne traite plus alors de la mondialisation de la culture; toute mondialisation est une affaire de cultures qui s'entrechoquent. 
Cela pourrait expliquer pourquoi une discipline comme l'ethnologie, que J.-P. Warnier considère comme la plus à même de traiter des questions de mondialisation de la culture, est effectivement sollicitée avec profit : le raisonnement du discours hostile autour de la mondialisation, qui ne rentre pas dans les critères formels des discours scientifiques entre autres économiques ou géographiques, peut au contraire être pris en charge par des considérations culturalistes. La mondialisation vue depuis les sociétés occidentales est imperceptible pratiquement car elle se confond avec elles; le détour par les sociétés non-occidentales aux prises avec cette mondialisation-occidentalisation la rend beaucoup plus concrète. L'auteur pratique alors en quelque sorte un ethnocentrisme inversé, en exagérant la distance qui le sépare de la culture depuis laquelle il parle. Comme il souhaite identifier des «turbulences culturelles» qui servent à la fois de point de départ et de point d'arrivée, le détour par la mondialisation va servir de point de vue à partir duquel va être construite, et comme découverte, la catégorie du local.

\section{Masse et unicité}

Les deux mouvements décrits, de la massification des productions culturelles et de la réduction des différences interculturelles, dessinent un monde où les mêmes éléments culturels sont produits à grande échelle et distribués partout dans le monde, remplaçant les spécificités locales : "(l')ultime avatar (de la mondialisation) : la thèse de la convergence ou standardisation culturelle sur une planète vue à travers la lorgnette exclusive et excluante des "communautés des consommateurs" (...), unité de base du libre déploiement de la totalité marchande 20 ». On retrouve ici le renversement de la perspective libérale, caractéristique des analyses autour de la mondialisation: comme dans le cadre du libéralisme et du raisonnement managérial, c'est la volonté de diminuer les coûts qui entraîne une standardisation de la production, ici la standardisation est prise comme postulat et comme point de départ d'une politique destructrice. Poussé à la limite, le raisonnement identifie alors une véritable intention des partisans de la raison libérale - les multinationales de la culture, représentées dans les organisations régulatrices - de modifier le regard porté sur la nature de la culture. Le raisonnement libéral n'est plus entièrement contenu dans une sphère économique qu'il a définie; il en sort dans une visée offensive contre d'autres ordres, en particulier le politique et la culture, et se répand géographiquement. Ainsi apparaît dans le 
discours la sphère de la culture mondiale, comme ensemble à la fois de productions d'œuvres d'art à visée esthétique et de contenus anthropologiques stables, défini comme la réunion des cultures nationales et non pas - comme il est prêté aux tenants de la mondialisation de la culture - l'intersection limitée à un petit nombre d'éléments communs présents partout.

Le phénomène du marché mondial est interprété comme le catalyseur de phénomènes internes au monde de l'art et liés à la modernité en général : les questions de la culture de masse d'une part, et du statut de l'art de l'autre. En effet, le concept d'«industries culturelles", qui fait le lien entre "cultures-tradition» et mondialisation, est associé aux "côtés négatifs de la modernité industrielle, incapable de transmettre une culture atteignant les sujets dans leurs profondeurs, réduite au pastiche, à l'inauthenticité et à la standardisation superficielle 21 ». Les industries culturelles sont définies comme produisant en série des produits identiques distribués partout dans le monde, quelle que soit l'identité de la population ciblée - ce mythème de la masse possède ici une archéologie post-moderne. La masse de produits culturels désigne en effet tant une quantité qu'une qualité. À la multiplication, résultat des procédés de reproduction technique des œuvres 22 s'ajoute une perte de substance de chaque objet démultiplié. On retrouve, dans les images de duplication sans substance dans la marchandise, le thème du simulacre ${ }^{23}$; la masse des objets mondialisés forme un système autonome et irrésistible dans la compulsion à la consommation qu'il crée ${ }^{24}$, très différente des modes traditionnels d'appréciation des œuvres d'art - qui sont au cœur de l'argumentation sur la mondialisation de la culture.

Cette transformation de la perception et de la réception des œuvres fait écho aux conclusions de W.Benjamin. En effet, il voit dans le développement de techniques de reproduction de masse des œuvres d'art une profonde transformation du rapport à celles-ci; la reproduction, en supprimant la notion d'authenticité puisqu'on ne peut plus guère parler de copie, supprime le poids de tradition entourant des œuvres anciennes - leur aura - en même temps qu'elle permet à chacun de se rapprocher de l'œuvre via sa représentation reproduite. Ce raisonnement informe nettement celui sur la mondialisation de la culture : les productions de masse détruisent alors les traditions non seulement par le jeu de l'organisation capitaliste standardisée de la production et de la distribution, qui privilégie les économies d'échelle, mais aussi parce que la reproduction en série 
détruit l'aura spécifique des objets uniques produits par la tradition, et modifie la perception qui en est faite. La production en série, qui permet à chacun de se rapprocher de l'œuvre, supprime ainsi la distance qui caractérise le "lointain» de l'œuvre d'art; elle abolit ce lointain en une concentration qui est exactement l'effet défini dans la mondialisation.

Si la masse indifférenciée apparaît comme le stade ultime de la mondialisation de la culture, la résistance à celle-ci passe par l'ancrage dans une singularité, dont l'unicité produit de la distinction : ainsi, pour $\mathrm{F}$. Wuilmart, la spécificité culturelle se conjugue à l'imagination individuelle du créateur pour produire le "relief» de l'œuvre. Celui-ci doit être préservé par la traduction qui doit veiller à conserver le sentiment d'étrangeté qu'il procurera à des lecteurs situés hors de son aire linguistique d'origine - autant dire son exotisme : «il s'agit de laisser transparaître l'étranger dans la langue maternelle 25 ». La résistance à la mondialisation de la culture passe donc ici par une préservation de la distance qui sépare de l'étranger.

\section{Préservation des cultures et politiques d'identité}

Cependant, les solutions préconisées face à la menace que représente la mondialisation de la culture sont plus complexes que le maintien à distance des cultures occidentales et non-occidentales. Trois grandes options sont ainsi présentées : l'ancrage maintenu dans l'utopie universaliste (les «promesses d'une planète démocratique unifiée par une culture universelle»), le renoncement (le fait de considérer la mondialisation comme la "cause d'une inéluctable perte d'identité") ou le choix de certains qui "militent pour affirmer leurs particularismes jusqu'à faire usage de la violence ${ }^{26}$ ». Ce dernier point fait apparaître une figure caractéristique des discours sur la mondialisation de la culture, qui est celle du groupe social attaché à sa différence et susceptible de la défendre par des moyens inquiétants. Ici, la figure des adversaires de la mondialisation de la culture non seulement sert de preuve à l'existence de celle-ci; mais ils sont considérés sous l'angle du «différencialisme», s'appuyant sur une identité culturelle - c'est-à-dire, ici, sur un groupe ethnique qu'ils chercheraient à protéger contre l'uniformisation résultant de la mondialisation. Comme l'a montré M.Wieviorka27, le discours sur la "différence» ou l'analyse dans le cadre de théories de l'ethnicité masquent fréquemment un discours racialisé. Les «traits culturels" identifiés reviennent en effet à un élargissement au mode de vie d'une 
approche phénotypique plus ou moins scientificisée. Le discours sur la mondialisation de la culture permet donc, sur fond d'une disparition progressive des spécificités des minorités (dont les auteurs peuvent par ailleurs se déclarer désolés), d'exprimer une hostilité vis-à-vis d'une formulation politique autonome de ce thème de la différence, c'est-à-dire des revendications appuyées sur une politique d'identité.

À cette perspective conflictuelle, les auteurs préfèrent substituer un discours de la prise en charge des "cultures-tradition" par des institutions internationales de la culture, qui mettent en place des politiques de préservation du patrimoine : Cette production [musicale] est susceptible d'être subventionnée par les États à des fins de préservation des musiques traditionnelles ou à titre de l'aide à la création ou à la sauvegarde du patrimoine artistique 28 ". L' "authenticité" des œuvres équivaut alors à leur conformité à une tradition exotique, et non pas à leur insertion dans l'histoire de l'art nationale. La justification de cette prise en charge s'appuie sur le postulat que «l'activité des industries culturelles et médiatiques ne se poursuit sur le long terme qu'en respectant des logiques économiques 29 ” - on retrouve une norme implicite de la participation forcée à un marché de la culture mondial qui provient directement des théories libérales, et qui implique le recours à une forme spécifique de rationalité. Les producteurs d'œurres issues des "cultures-tradition" seraient moins bien armés que leurs homologues occidentaux pour en faire usage, ce qui conduit à un appel à une restriction des règles d'airain du marché par la mise en place de régulations supra-nationales. Les productions culturelles non occidentales restent ainsi sous contrôle des institutions internationales, soit par l'intermédiaire de la commande publique dans une perspective muséographique, soit par celui de la régulation du marché.

Une alternative présentée à cette culture-musée est le mélange, formulée dans les discours sur l'hybridité, la créolité, etc. Ces mélanges n'aboutissent pas à une réduction des différences interculturelles - l'«homogénéisation» - mais à la création de cultures nouvelles conjuguant tradition et modernité. La caractéristique principale de cette hybridité est qu'elle fait cohabiter les deux registres de manière naturellement pacifiée, et évacue donc la potentialité d'un conflit autour des termes par lesquels accèdent à cette modernité les populations des sociétés dépendantes - qui sont au premier chef concernées par ce thème de l'hybridité, bien plus par exemple que les mélanges entre populations européennes. Alors que 
la mondialisation est dotée dès le départ d'une sémantique péjorative, l'hybridité est systématiquement connotée positivement; elle est l'avers de la médaille dont la mondialisation de la culture est le revers. En ce sens, elle ne s'oppose pas à elle mais la complète dans les discours, de la même manière qu'un modèle positif complète un modèle négatif. Je n'ai pas intégré dans mon corpus de textes directement souverainistes, qui sortaient de mon objet; les textes portant sur la mondialisation de la culture qui fréquemment convoquent un imaginaire national, n'ont donc pas été écrits dans une perspective directement nationaliste, ce qui explique le possible recours positif au thème de l'hybridité, absent des discours d'extrêmedroite attachés au thème de la pureté de la race. Si, dans les textes sur la mondialisation de la culture, le thème de l'hybridité fait nettement plus appel à la vision d'une entente naturelle entre des groupes sociaux différents qu'à des perspectives racialisées, il ne faut pas oublier qu'elles en forment néanmoins l'arrière-plan : dans son archéologie biologique, l'hybridation parle d'une culture portée par une nature, transmissible par la filiation et sujette à croisements. Par ailleurs, l'hybridation n'a pas pour horizon la réduction des différences par dilution réciproque des cultures : elle crée de nouvelles catégories identitaires, ce dont les auteurs, en toute logique, se félicitent : ils soulignent que de cette manière, l'hybridation contribue à lutter contre la mondialisation de la culture. Quand cette hybridation n'a pas pour objectif la fixation de catégories identitaires mais un mouvement perpétuel des cultures, elle oppose la créolité (figée) à la créolisation (sans fin) dans un éloge d'une société vouée au changement ou au "Chaos-monde» 30 .

\section{Conclusion}

Les discours hostiles à la mondialisation couvrent un ensemble étendu de domaines, hors le ressassement d'une liste limitée d'arguments hostiles au néo-libéralisme. De par la plasticité de leurs thèmes fondamentaux, ils permettent une grande créativité en ce qui concerne les thèmes qu'ils couvrent et les expressions politiques qu'ils autorisent - comme ici le cas de la mondialisation de la culture. Les dérivations possibles à partir de ce corps central d'arguments anti-mondialisation se traduisent ainsi en hostilité à une mondialisation spécifique, avec un contenu essentiellement centré autour de la défense de la localité, c'est-à-dire ici de la nation. Les développements de ce discours prennent ainsi un tour nettement souverainiste. II est intéressant de noter qu'il n'y demeure pas et 
glisse sur les signifiants partagés avec l'extrême-droite pour parvenir à des conclusions originales : ainsi, un argument interprétant les différences culturelles comme source de conflit - très proche de perspectives ethno-différencialistes ${ }^{31}$ - mène à une louange de l'hybridité et du mélange culturels, dans la perspective de la création de nouveaux groupes culturels. Le discours sur la mondialisation de la culture, sur un terreau d'anti-libéralisme économique et de revalorisation du local, ajoute donc un élément propre, qui est la dénonciation des politiques d'identité "différencialistes" - tout en partant d'un point de départ de défense des différences face à la mondialisation. Nous nous trouvons donc face à un univers du discours fluide, dans lequel toutes les expressions politiques prennent place : il n'embraie sur aucune préconisation en termes d'action politique, car il est créé comme un objet plastique dont l'usage dépendra des contours du mouvement politique qui se l'appropriera.

\author{
Brigitte Beauzamy \\ CADIS/GTMS (EHESS) - CIR
}


1. Henry Hinberg, "La culture dans les mondialisations" in Michel von Cromphart (dir), La mondialisation, gouffre ou tremplin? Paris, L'Harmattan 2001, p.197-206 (Ce livre réunit des textes provenant aussi bien de responsables politiques, d'industriels, de praticiens de différentes branches, que de chercheurs).

2. Jean-Pierre Warnier, La mondialisation de la culture, Paris, La Découverte coll. Repères, 1999, p.6.

3. Henry Hinberg, ibid.

4. Sur les rapports entre classification et traitement des différences, voir Michel Foucault, Les Mots et les choses, Paris, Gallimard, 1966, p. 150-176.

5. Jean-Pierre Warnier, op. cit. p. 7.

6. Ibid, p. 11.

7. Ibid, p. 9-10.

8. Françoise Wuilmart, "Mondialisation, écriture et traduction", in Michel von Cromphart (dir), La mondialisation, gouffre ou tremplin? op.cit. p. 207-223

9. J. Amery, Par delà le crime et le châtiment, essai pour surmonter l'insurmontable, Actes Sud, Arles, trad.fr. (de F. Wuilmart) 1995, cité par F. Wuilmart, op. cit. p. 208 sq. Elle précise que J. Amery est un écrivain «juif autrichien (...) banni de sa terre natale et déporté à Auschwitz".

10. Françoise Wuilmart, "Mondialisation, écriture et traduction», op.cit. p. 211. L'argument de la langue a par ailleurs été largement utilisé dans des réflexions racialisées sur la culture, le paradigme philologique ayant par exemple défini des ensembles "sémites".

11. Jean-Pierre Warnier, op. cit. p. 11.

12. Ibid, p. 30.

13. Ibid, p. 60.

14. Ibid, respectivement p. 112 et 77.

15. Françoise Wuilmart, op. cit. p. 211-212.

16. Ibid, p. 217.

17. Ibid, p. 215.

18. Jean-Pierre Warnier, op. cit. p. 6. C'est moi qui souligne.

19. Serge Cordellier, introduction à (dir.) La mondialisation au-delà des mythes, op.cit. p.10.

20. Armand Mattelart, Histoire de l'utopie planétaire, op.cit. p. 12.

21. Jean-Pierre Warnier, op.cit. p. 16.

22. Walter Benjamin, "L'œuvre d'art à l'ère de sa reproductibilité technique" (1êre version, 1935) in CEuvres III, trad. Fr. Paris, Gallimard, 2000, p. 67-113.

23. Jean Baudrillard, Simulacres et simulation, Paris, Galilée 1981. Le thème du simili est déjà présent dans les analyses de R.Barthes, en particulier Mythologies, op.cit., mais il prend chez les post-modernes une signification du divorce de l'apparence et du réel, et non plus l'imitation à l'usage des classes moyennes ou populaires des objets de luxe caractérisant le mode de vie des classes aisées.

24. Jean Baudrillard, La Société de consommation, Paris, Denoël 1970. Voir aussi Le Système des objets, Paris, Gallimard 1968.

25. Françoise Wuilmart, «Mondialisation, écriture et traduction», op.cit. p 218. 


\section{Brigitte Beauzamy}

26. Jean-Pierre Warnier, op.cit. p. 3.

27. Michel Wieviorka, La Différence, Paris, Balland 2001.

28. Jean-Pierre Warnier, op.cit. p. 48.

29. Ibid, p. 55.

30. L'expression est du philosophe Edouard Glissant, dans un entretien publié dans le numéro cité des "Périphériques vous parlent", 